\title{
Wear Behaviour and Characteristics of Worn - out Valves used in LPG - run Retrofitted Gasoline Engines
}

\author{
[Pandey Ajay, Mandloi R. K.]
}

\begin{abstract}
Valves used in passenger car engines, running on gasoline, operate in a very hostile environment that is characterized by high temperatures and pressures, impact loading, thermal stresses, and fatigue loading. These engines, when in operation, result in generation of temperatures that are close to $600^{\circ} \mathrm{C}$ inside the intake valve; the corresponding value for the exhaust valve being $700^{\circ} \mathrm{C}$ to $800^{\circ} \mathrm{C}$, respectively. However, the exhaust valve temperatures can shoot up to $950^{\circ} \mathrm{C}$ for a retrofitted LPG - run gasoline engine. Engine valves, being subjected to such high temperature and pressures, are extremely vulnerable against wear and consequent failure. Wear failure of valves is a commonly encountered phenomenon and the fatigue crack growth has its own role to play in contributing to the failure. The wear mechanisms in valves of LPG - run retrofitted engines have been found to be a combination of oxidation and adhesive wear, though valves also fail due to surface erosion and corrosion. Since retrofitting is a common practice in many developing countries, it is important to understand and analyze the wear behavior and characteristics of valves originally designed for gasoline engines but subsequently used on LPG run engines. In this work, wear analysis of a number of such worn - out engine valves was carried out for analyzing the failure patterns, failure causes and failure mechanisms after being in operation at high temperatures for a considerable period of time. A pin - on - disc wear tester was employed for carrying out exhaustive wear tests on valve specimens made from inlet and exhaust valves. The wear patterns thus obtained were analyzed for understanding the progressive growth of wear and eventual failure of engine valves.
\end{abstract}

Keywords-valves, retrofitting, LPG, wear, oxidation, adhesive wear

\section{Introduction}

Valves of automobile engines are subjected to significantly high temperatures and pressures, impact loading, thermal stresses, and exhibit a pronounced effect of fatigue loading too, when analyzed for failure. There are four distinct types of failure mechanisms for a valve or valve component: brittle failure, ductile failure, wear, and corrosion [1].

(Pandey Ajay)

line 1 Maulana Azad National Institute of Technology line 2: India

(Mandloi R. K.)

line 1 Maulana Azad National Institute of Technology line 2: India
Wear failure of valves is a commonly encountered phenomenon and the fatigue crack growth has its own role to play in contributing to the failure. The wear mechanism in exhaust valves of heavy duty engines has been found to be a combination of oxidation and adhesive wear [2]. Valves also fail due to surface erosion and corrosion. The erosion corrosion of exhaust valves ("valve guttering") is a recognized failure mode in internal combustion engines [3]. Valve failure may occur due to valve recession caused by loss of material from the seat of the valve and increases with increasing engine load [4] .Valve recession occurs when wear of the valve or seat inserts in an automotive engine cause the valve to sink or recede into the seat insert. Excessive recession leads to valves not seating correctly and cylinder pressure loss. Leaking hot combustion gases can also cause valve guttering or torching which accelerates valve failure [5].

The failure of the contact conical surface of valves is mainly due to elastic and plastic deformation, the fatigue micro-crack, and spalling [6]. Exhaust valve stem generally fails by overheating which manifests itself in terms of significant hardness loss and extensive surface oxidation and fretting / galling on the valve stem [7]. The middle portion of the stem exhibits a longitudinal fretting damage. High temperatures result in reducing the hardness of the valve material and also affect its fatigue properties [8].

In an internal combustion engine, pressures and temperatures affecting the valves vary with fuel type and the combustion characteristics of the fuel. Consequently, valves are exposed to different dynamic and thermal stresses [9].

Valve systems of LPG - run retrofitted gasoline engines are subjected to harsh operating conditions. These conditions owe their genesis to high temperatures across different sections, cyclic and impact loads, micro sliding and the effects caused by exhaust gases. Valve wear has always been a serious problem and compounded by retrofitting wherein a valve designed for usage in gasoline - run passenger cars is used for LPG applications too where the operating temperature has a tendency to shoot up considerably. Hostile operating environments also contribute to valve recession problems, both qualitatively and quantitatively. Since the exhaust valves operate at relatively higher temperatures, they are exposed to thermal loads and chemical corrosion. The intake valves, which are not subjected to such extreme thermal loading, are cooled by incoming gases, thermal transmission at the seat, and by other means. This necessitates the use of an advanced material for exhaust valves in comparison to inlet valves. Whereas the inlet valves are made up of martensitic steel, the exhaust valves are made up of austenitic steel. 


\section{Experimental Details}

\section{A. Valve Specifications}

The valves chosen for this experimental investigation were standard poppet valves used in LPG - run, retrofitted passenger car gasoline engines in India. The valve specifications are $\mathrm{L} / \mathrm{TH} / \mathrm{D} / 1, \alpha 45^{\circ}$ (inlet valve) and $\mathrm{S} / \mathrm{TF} / \mathrm{D} / 1$, $\alpha 45^{\circ}$ (exhaust valve). The inlet valve dimensions are $31.6 \mathrm{~mm}$ (D) $\times 7.0 \mathrm{~mm}(\mathrm{~d}) \times 110 \mathrm{~mm}$ (l) whereas the exhaust valve dimensions are $27.0 \mathrm{~mm}(\mathrm{D}) \times 7.0 \mathrm{~mm}(\mathrm{~d}) \times 119.5 \mathrm{~mm}(\mathrm{l})$.

\section{B. Sample Preparation}

For doing wear testing, tests were performed on the specimens made from inlet and exhaust valves, both worn out and new, utilizing a Meta - cut DCM for cutting and separating the disc element $(10 \mathrm{~mm}$ diameter $)$ and the stem element $(25 \mathrm{~mm}$ length and $5 \mathrm{~mm}$ diameter). The faces of these specimens were polished by diamond paste, cleaned in acetone and dried prior to wear tests on POD wear tester.

Specimens of standard dimensions were prepared using used and new exhaust and inlet valves. The preparation involves cutting and surface finishing with different grades of emery papers, clothing, and finally etching by an etching solution with $2 \% \mathrm{HNO} 3$ and $98 \%$ methanol / acetone solution. Each specimen is etched for 3 to 5 minutes and then dried completely in oven prior to their microstructure analysis through a Scanning Electron microscope (SEM).

\section{Experimentation}

The wear analysis of prepared valve specimens was performed by testing them on a Pin - on - Disk wear tester (Fig. 1). The pin - on - disk testing consists of a rotating disk in contact with a fixed pin with a spherical top (ASTM G99 04). The specimen was located in a holder in such a way so as to bring it in contact with the plate $(19 \mathrm{~cm}$ diameter, $9 \mathrm{~mm}$ thickness) to ensure rubbing between contact surfaces. During the wear testing, the parameter values were: a constant load of $20 \mathrm{~N}$, testing time duration of $15-60$ minutes, rotational speed of Pin - on - Disk as 200 RPM, and the wear track radius as $40 \mathrm{~mm}$. The variation patterns of wear with time were obtained. The wear patterns thus obtained for worn out and new specimens were studied and analyzed to understand the building up and growth of wear. The worn out valve samples (both head \& stem) were benchmarked against corresponding new specimen samples.

The microstructure analysis was performed for failed and new valve heads (both inlet and exhaust). The testing was done on JSM - 6390A (JEOL) Analytical Scanning Electron Microscope and the resolution employed was X5000 [10].

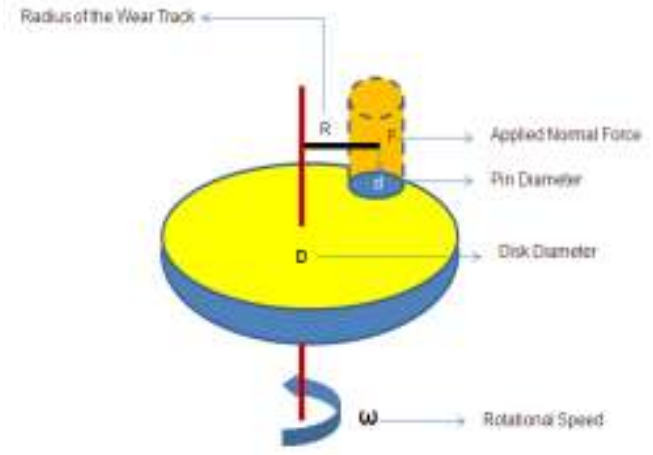

Figure 1 Schematic of the Pin-on-disk wear tester

\section{Observations and Discussion}

Though exhaustive testing has been done on many worn out and new samples prepared out of valves used in LPG - run retrofitted gasoline engines, only a few representative curves are reproduced here.

The variation of wear with respect to time (Fig. 2) for a failed exhaust valve exhibits a definite similarity with oxidative wear mechanism. Corresponding to a particular load, the surface oxidation phenomenon is beneficial as it reduces the depletion of material. This is particularly true at high sliding speeds. The softened oxide film acts typically like a lubricant layer that protects the metallic substrate. The oxide films formed prevent direct metal - to - metal contact and also result in reduction in the coefficient of friction on contact surfaces, thereby reducing adhesive and deformation controlled wear. The oxidation of material is closely linked to the existing operating temperatures and therefore is on expected lines as the exhaust valve in an LPG - run retrofitted gasoline engine usually encounters high temperature. However, the oxide layers formed on the material surface start wearing off with passage of time. The wear magnitude varies from a pretty low value of 0.39 microns to 124.41 microns as shown (Fig.2). The nature of the curve (Fig. 3) for a new exhaust valve head shows steady state wear after the initial zone of instability. The crests and troughs in this curve may be attributable to presence and sudden appearing of highly abrasive particles that raise or lift the pin on the POD tester, thereby creating sharp changes in wear magnitude. The magnitude of wear varies from a minimum value of 0.24 microns to a maximum value of 6.31 microns as is evident (Fig. 3).

For a failed exhaust valve stem, the wear variation pattern is more regular and on predictable lines (Fig. 4). Its magnitude varies from 0.68 microns to 78.41 microns. The wear V/s time curve (Fig. 5) indicates that the stem is relatively softer than the disc and wears out consistently. As shown, wear varies from 0.72 microns (minimum) to 62.69 microns (maximum). 
Proc. of the Intl. Conf. on Advances in Civil, Structural and Mechanical Engineering - ACSM 2015.

Copyright $(\odot$ Institute of Research Engineers and Doctors, USA .All rights reserved.

ISBN: 978-1-63248-039-2 doi: 10.15224/ 978-1-63248-039-2-98

The variation of wear w. r. t. time for a failed inlet valve head is shown in Fig. 6. The variation reflects an almost steady wear condition with no noticeable abnormal behavior across any zone. The corresponding curve for a new inlet valve shown in Fig. 7 exhibits a wear pattern that is quite akin to adhesive wear.

For a failed inlet valve stem, the variation curve (Fig.8) shows removal of surface films with time and the building up of steady state wear whereas the corresponding one (Fig.9) for a new valve stem is characterized by adhesive wear, presence of surface particles / surface films, and graphite flakes.

The initial portion of many such graphs, in all probability, may be an indication of the errors that creep in on account of improper clearance, erroneous disc / specimen fixing, setting errors, etc. This leads to some instability in the initial portion. However, beyond the initial region, the nature of the curve becomes more predictable and uniform.

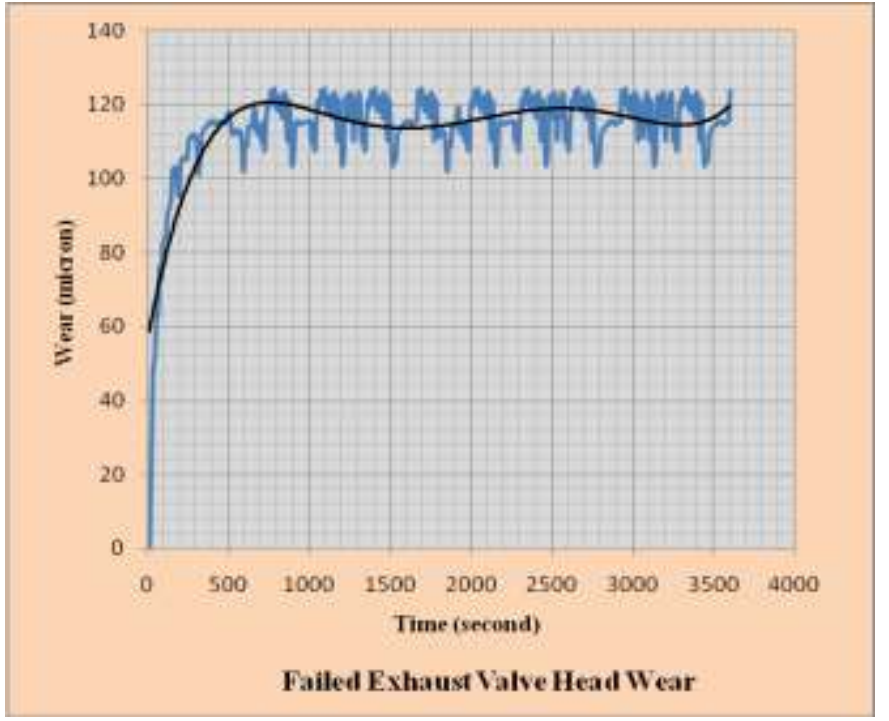

Figure 2 Wear variation curve for a failed exhaust valve head

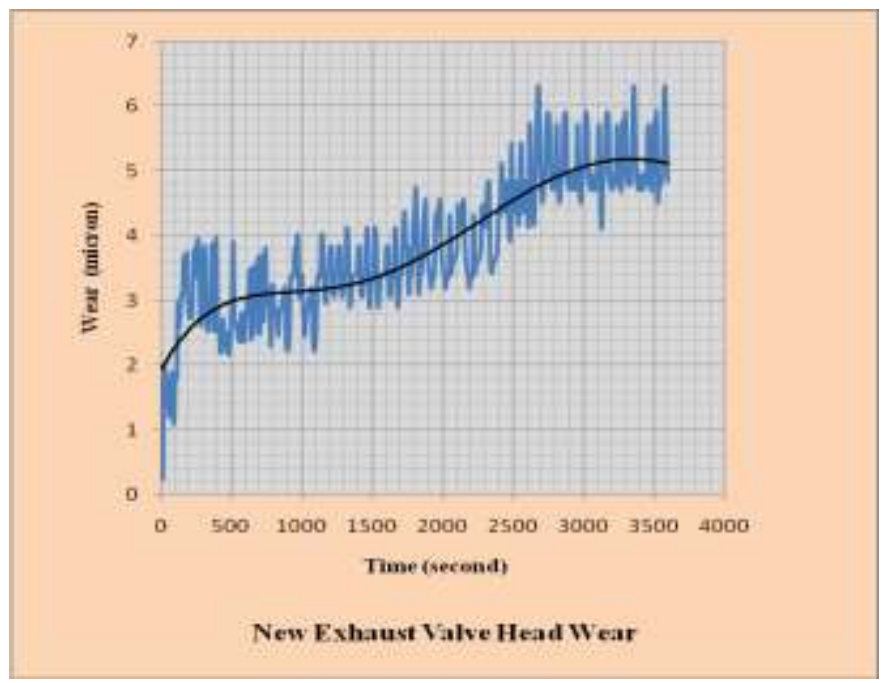

Figure 3 Wear variation curve for a new exhaust valve head

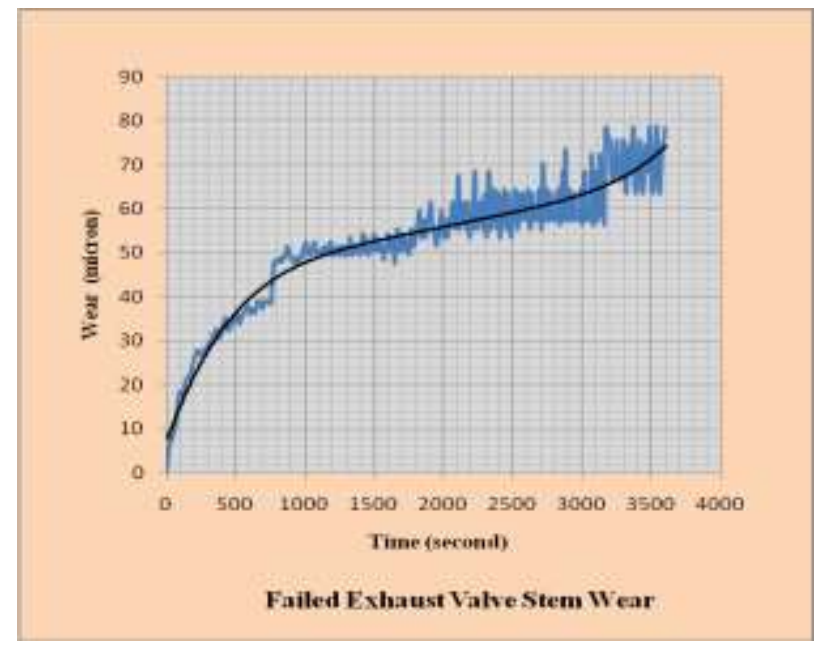

Figure 4 Wear variation curve for a failed exhaust valve stem

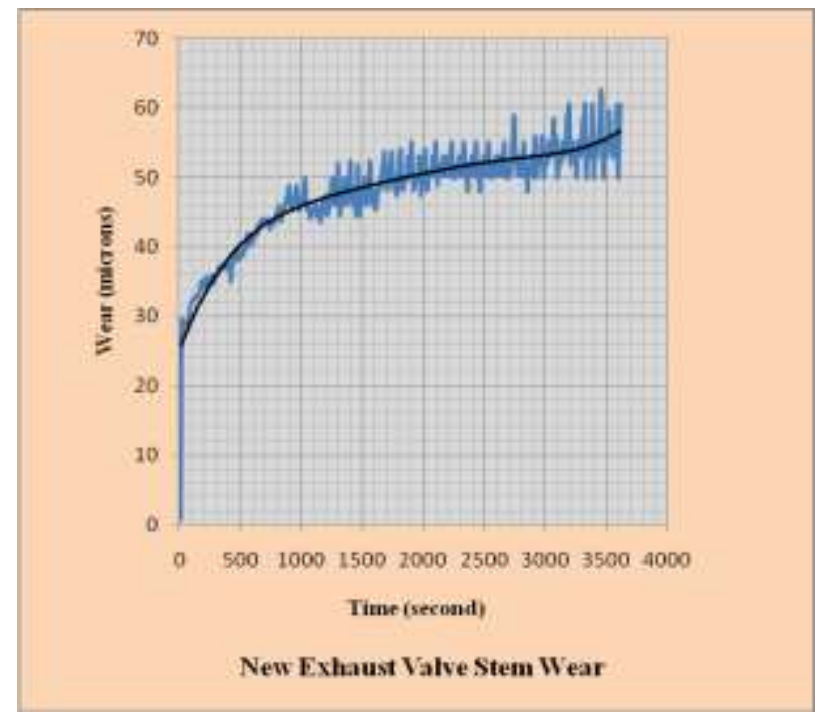

Figure 5 Wear variation curve for a new exhaust valve stem

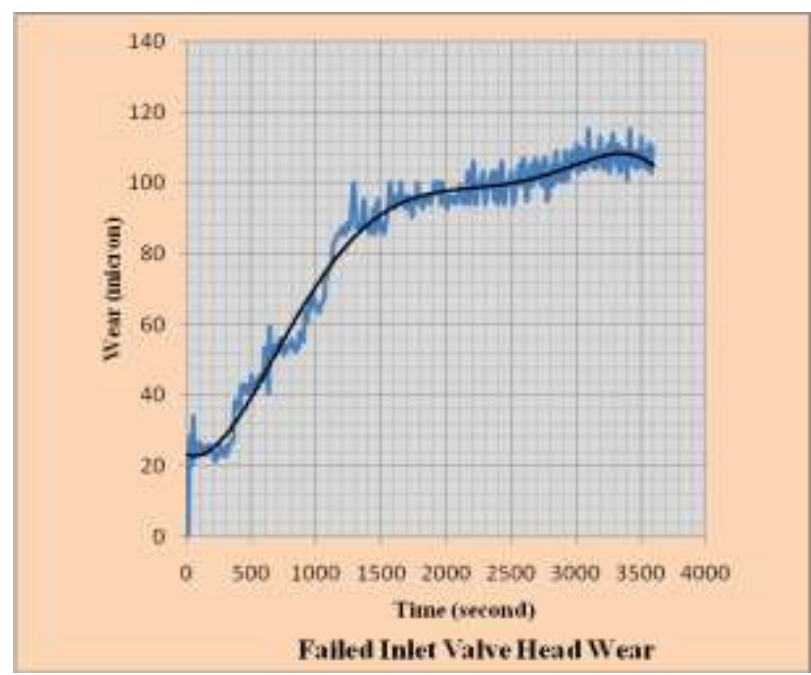

Figure 6 Wear variation curve for a failed inlet valve head 
Proc. of the Intl. Conf. on Advances in Civil, Structural and Mechanical Engineering - ACSM 2015.

Copyright $(\odot$ Institute of Research Engineers and Doctors, USA .All rights reserved.

ISBN: 978-1-63248-039-2 doi: 10.15224/ 978-1-63248-039-2-98

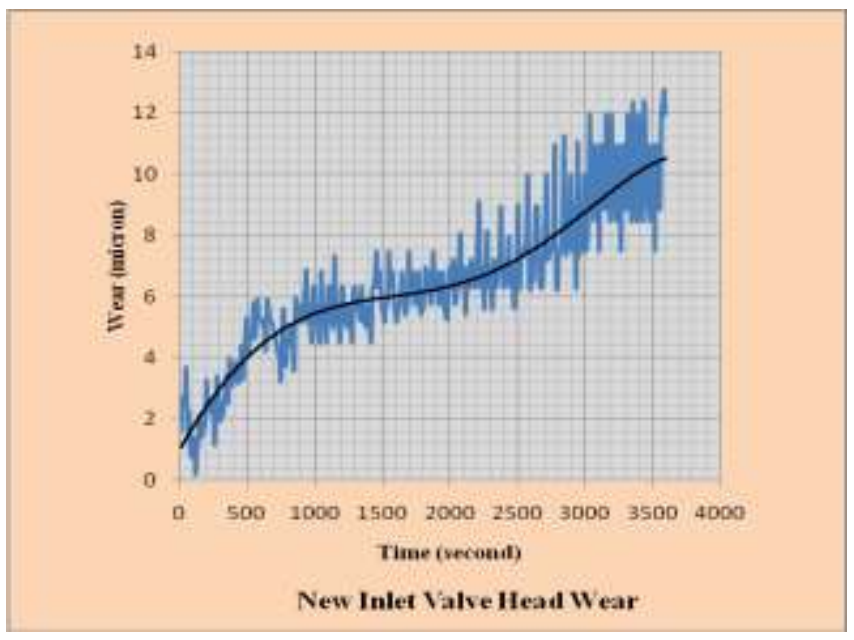

Figure 7 Wear variation curve for a new inlet valve head

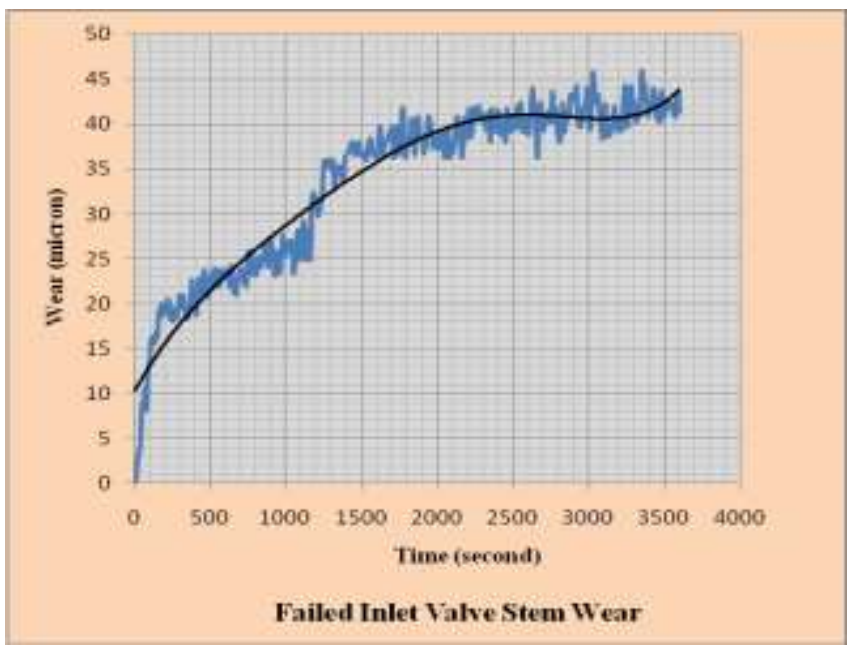

Figure 8 Wear variation curve for a failed inlet valve stem

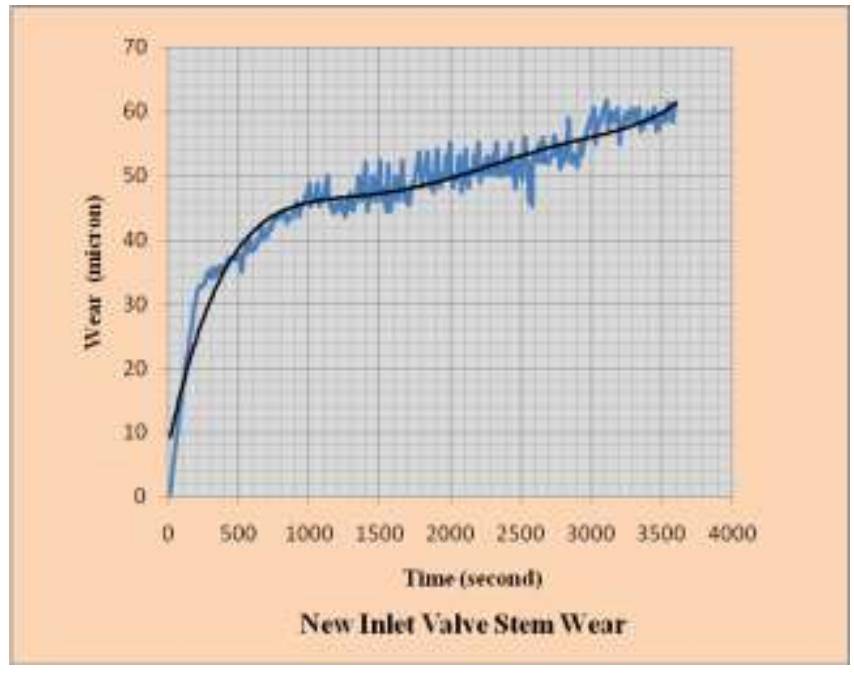

Figure 9 Wear variation curve for a new inlet valve stem

SEM images depicting the microstructure of new \& failed intake \& exhaust valves are shown at X5000 resolution (Fig. $10 \&$ Fig. 11). The white colour spots in the images indicate the presence of oxides whereas blackish grey patches indicate the presence of carbides in the valve material as also the effect of corrosion which becomes more pronounced at high temperatures. A fine distribution of carbides indicates increased material hardness but a coarse distribution of carbides makes them shift towards the grain boundaries with an accompanying reduction in the hardness and weakening of the material. The grain boundaries visible in the SEM image indicates that grains are broken and are not uniformly distributed. The size of grains, which is an indication of material strength, increases after working at high temperatures. Big size grains indicate lower strength whereas small size of grains (or finer grain sizes) indicates higher material strength. An increase in the size of the grains, or elongated grains, in SEM images of failed valves indicates that the valve material strength has come down after being subjected to high temperatures for considerable periods.

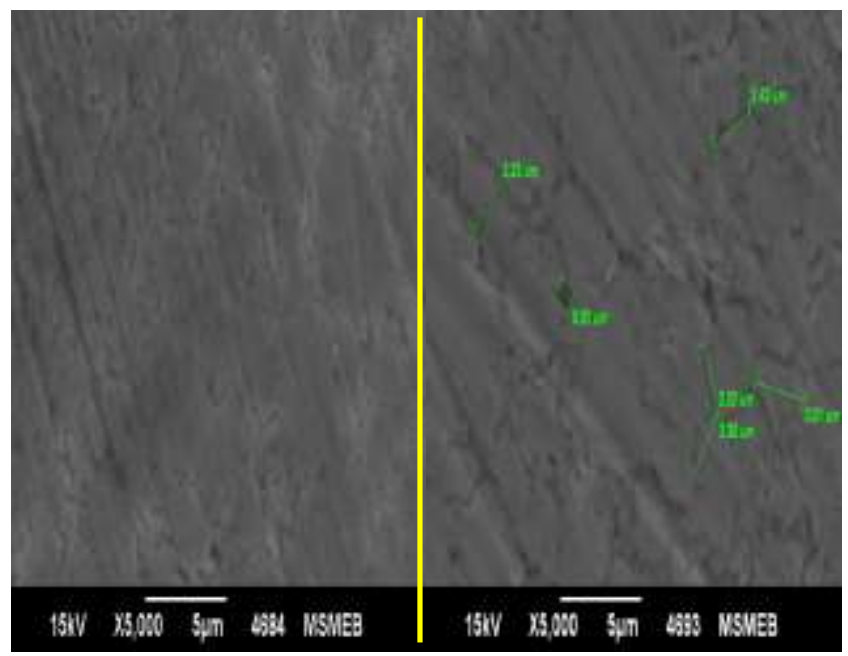

Figure 10 SEM image of a new exhaust valve head (left) and failed exhaust valve head (right) at $\mathrm{X} 5000$

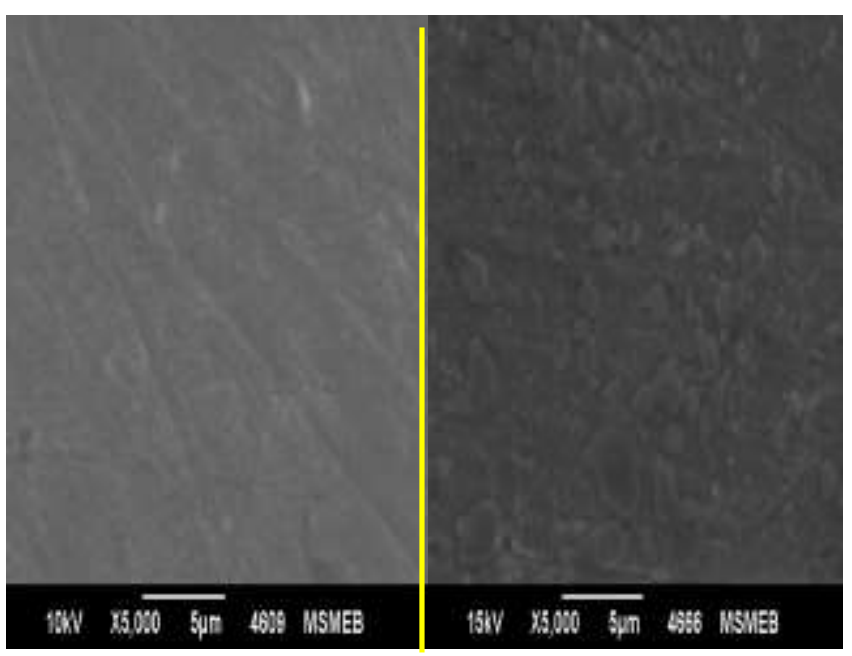

Figure 11 SEM image of a new exhaust valve head (left) and failed exhaust valve head (right) at X5000 


\section{Conclusion}

The wear of valves in LPG - run retrofitted gasoline engines used in passenger cars is a complex phenomenon as a number of failure modes like oxidative wear, adhesive wear / material transfer, abrasive wear and plastic deformation, erosion and corrosion interact with each other and contribute collectively to the failure of the valve. Surface oxidation or parting agents are also found to play a significant role in the wear of valves. High contact stresses, poor seat lubrication, incompatible materials, and relative sliding are some of the primary causes of adhesive wear which is indicated by material transfer. It may be caused by micro - welding or bonding between the contact surfaces due to high local pressure. Localized surface contact results in surface irregularities (projections or asperities) on the mating surfaces to go through plastic deformation. The gouging and scoring on the contact surfaces are a reflection of abrasive wear whereas abrasion and radial flow serve as clear indicators of plastic deformation. The magnitude of abrasive wear is significantly enhanced by relative sliding of the mating surfaces during engine operation. Other influencing factors are - presence of hard carbides, trapped wear debris, combustion products, contaminant particles from oil, fuel and air, etc. The wear debris formed ultimately results in clear detachment of particles from the valve and valve seat. High values of coefficient of friction and sliding effect between the valve and insert seat are the factors that may contribute significantly to the seat surface deformation or radial flow and subsequent wear. Corrosive wear is also observed in most exhaust valves and is attributable to the presence of a harsh chemical environment and high temperature. A comparison of the microstructure of failed valves and new valves reveals that the size of grains, grain boundaries, and distribution of carbide particles is affected by high temperature operating conditions and has a serious impact on the useful life of the valves by not only adding to crack initiation and its propagation but by influencing the wear pattern also.

\section{Acknowledgment}

The authors gratefully acknowledge the support provided by their institute MANIT, Bhopal (India).

\section{References}

[1] D. J. Benac and R. A. Page, "Integrating Design, Maintenance, and Failure Analysis to Increase Structural Valve Integrity". ASM International, PFANF83, 2001, pp. $31-43$.

[2] P. Forsberg, P. Hollman and S. Jacobson, "Wear mechanism study of exhaust valve system in modern heavy duty combustion engines", Wear , Volume 271, 2011, pp. 2477-2484.

[3] C.G. Scott, et al, "The erosion - corrosion of nickel - base diesel engine exhaust valves". Wear 181-183, 1995,pp. $485-494$.

[4] C. V. Subba Rao and K. Vijaya Kumar Reddy, "Performance Analysis And Wear Of I.C. Engine Valve And Seat Inserts Using Jatropha Methyl Esters", International J. of Engg. Research \& Indu. Appls. (IJERIA). Vol. 4, No. III, 2011, pp. 177 - 188.

[5] Lewis, R. and Dwyer - Joyce, R.S., “Combating automotive engine valve recession: a case study". Tribology and Lubrication Technology, 59 (10), 2003, pp. 48-51.
[6] Nurten Vardar and Ahmet Ekerim, "Investigation of Exhaust Valve Failure in Heavy - duty Diesel Engine", 23 (4), 2010, pp. 493 - 499.

[7] Yun - cai Zhao and Hang - zhi Yan , "Experimental study on wear failure course of gas - valve / valve - seat in engine", Journal of Central South University of Technology, Volume 12, Issue 1, 2005, pp. $243-$ 246.

[8] Stefanie Stanzl-Tschegg "Very high cycle fatigue measuring techniques" International Journal of Fatigue 60, 2014, pp. 2-17.

[9] M. I. Karamangil, A. Avci and H. Bilal, "Investigation of the effect of different carbon film thickness on the exhaust valve". Heat Mass Transfer, 44, 2008, pp. $587-598$.

[10] J. Man, M. Valtr, M. Petrenec, J. Dluhoš, I. Kube`naa, K. Obrtlik, J. Polak "AFM and SEM-FEG study on fundamental mechanisms leading to fatigue crack initiation" International Journal of Fatigue 2014 (Article in press).

About Author (s):

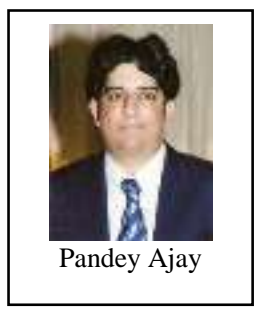

\section{Specialization / Interest Area}

Mechanics \& Automobile Engineering

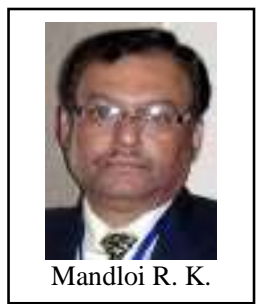

Specialization / Interest Area

Alternative Fuels, Automobile

Engineering, IC Engines,

Production Engineering. 